\title{
Analysis of osteoblast, osteoclast levels and radiographic patterns in the healing process of bone fractures (preliminary research)
}

\author{
Norlaila Sarifah ${ }^{*}$, Lusi Epsilawati ${ }^{2}$ iD , Azhari², Mieke Hermiawati Satari ${ }^{3}$, \\ Bambang Pontjo Priosoeryanto ${ }^{4}$ (iD, Isnur Hatta ${ }^{5}$, Annisa Fitriyana ${ }^{6}$
}

\begin{abstract}
Objectives: The healing process of a bone fracture goes through many phases. This study aimed to examine the analysis of bone fracture healing between osteoblasts and osteoclast numbers and radiographic patterns.

Materials and Methods: The study used 12 male Wistar rats with an incomplete fracture in the right femur made by a dental tapered bur with $0.3 \mathrm{~mm}$ in length and $0.2 \mathrm{~mm}$ in depth. Digital radiographic examinations were carried out on days $0,5,10,17$, and 25 after fracturing in a lateral position. Radiographic analysis was performed using Image-J to obtain changes in the value of length and depth in the healing area. The number of osteoblasts and osteoclasts was determined using a microscope. The study was conducted to determine the radiopaque and radiolucent patterns, as well as the number of osteoblasts and osteoclasts.
\end{abstract}

${ }^{1}$ Department of Dentomaxillofacia Radiology, Faculty of Dentistry, Universitas Lambung Mangkurat, Banjarmasin, Indonesia 70236

${ }^{2}$ Department of Dentomaxillofacial Radiology, Faculty of Dentistry, Univer sitas Padjadjaran, Bandung, Indonesia 40132

${ }^{3}$ Department of Oral Biology, Faculty of Dentistry, Universitas Padjadjaran Bandung, Indonesia 40132

${ }^{4}$ Division of Veterinary Pathology, Department of Veterinary Clinic, Reproduction and Pathology, Faculty of Veterinary Medicine, Institut Pertanian Bogor, Bogor, Indonesia 16680

${ }^{5}$ Department of Public Health, Faculty of Dentistry, Universitas Lambung Mangkurat, Banjarmasin, Indonesia 70236

${ }^{6}$ Faculty of Dentistry, Universitas Lambung Mangkurat, Banjarmasin, Indonesia 70236

* Correspondence to:

Norlaila Sarifah

冈norlaila.sarifah@ulm.ac.id

Received on: November 2021 Revised on: December 2021 Accepted on: December 2021 2021;5(3)106-11. https://doi.org/10.32793/jrdi.v5i3.740

\section{INTRODUCTION}

Bone is an organ of the skeletal system that provides shape, structure, motion, and protection for the human body. The primary function of bone is to provide a strong and mechanically optimal support structure for soft tissues and muscles. ${ }^{1,2}$ the bone is broken due to mechanical forces that the body cannot tolerate. Most cases of fracture are caused by trauma or certain bone diseases. Fractures are divided into three types based on etiology: trauma, fatigue, and pathological. Trauma is the most common cause of fracture. ${ }^{1}$

The World Health Organization (WHO) states that in 2008 there were about 13 million fracture cases in the world. The prevalence of this case was around $2.7 \%$ and increased in 2009 to 18 million people with a plurality of $4.2 \%$. In 2010 it increased to 21 million people with a majority of $3.5 \%$. These
Results: This study resulted in a change in the radiograph pattern. Callus formation resulted in fracture areas with a smaller distance from day 0 to day 25. The bone healing process begins with granulation tissue formation, followed by the gradual replacement of the connective tissue and bone. This process is comparable to the increase in osteoblasts up to day 25, which blocks bone resorption. Osteoclasts regulate bone resorption, and their number increases after 10 and 17 days to replace bone formation. Osteoclasts decline after 25 days because osteoblasts inhibit them, which control bone formation.

Conclusion: The conclusions were obtained there are changes in the radiograph pattern. The radiopaque increased while the radiolucent decreased; the osteoclast pattern tended to be stable and lowered while the osteoblasts increased during the fracture healing process. The correlation of all the factors is very closely related.

Keywords: Bone fracture, healing process, osteoblast, osteoclast, radiographic pattern

Cite this article: Sarifah N, Epsilawati L, Azhari, Satari MH, et al. Analysis of osteoblast, osteoclast levels and radiographic patterns in the healing process of bone fractures (preliminary research). Jurnal Radiologi Dentomaksilofasial Indonesia

Fracture is a condition where the continuity of fractures include incidents of accidents, sports injuries, and others. ${ }^{3}$ Fracture cases have been recorded in the Indonesian National Basic Health
Research (Riskesdas) conducted by the Indonesian Ministry of Health. In the Riskesdas report, it was stated that in $2007 \mathbf{7 . 5 \%}$ of the Indonesian population had experienced fractures, and this number continues to increase every year. For example, in 2013, the incidence of fractures went from $7.5 \%$ in 2007 to $8.5 \%$. In 2018 , there was an increase again where $9.2 \%$ of the Indonesian population had fractures. Based on this data, it can be concluded that in 2018 there were around $26,312,000$ people who experienced fractures out of 286 million Indonesian people in 2018. This incident was recorded as a reasonably significant incident. ${ }^{4}$

The fracture healing process will generally repair bone damage based on cellular composition, structure, and biomechanical function before the injury, but about $10 \%$ of fractures will not heal. Fracture healing is a complex process that includes inflammation, repair, and remodelling phases. It begins with the occurrence of a hematoma 
characterized by hypoxia, activation of complement and the coagulation cascade, release of inflammatory cytokines, and recruitment of immune cells within minutes of injury. The inflammatory phase begins with clearing debris, thereby limiting tissue damage. Next, endothelia cells secrete inhibitors, initiating soft callus formation and ultimately bone regeneration. Thus, a balance between pro-and anti-inflammatory events is critical, as disruption, enhancement, or prolonged inflammation is thought to impair fracture healing. ${ }^{5,6}$

Osteoblasts and osteoclasts can be used as parameters for the severity or cure of a disease. If a bone fracture occurs, the number of osteoblasts will increase, indicating the remodelling process in the fractured bone. Osteoblast cells play a role in bone formation and regeneration by producing, secreting, depositing, and mineralizing the bone matrix. In the callus formation phase, the number of osteoblast cells has not reached the normal value because they continue to proliferate until they reach their peak value in the remodelling phase. The number of osteoblasts will return to normal values after the remodelling process is complete and the healing process has ended. ${ }^{7,8}$

Osteoclasts will increase in the early phase of inflammation because of their function as resorption of damaged bone. At the same time, the number of osteoblasts will increase in the proliferative phase, which will act as bone-forming. The healing phase consists of 3 stages: the Inflammation Phase, divided into early inflammation (hemostasis phase) and late inflammation, which occurs from day 0 to day five after the injury. The proliferative phase, which includes three main processes: Neoangiogenesis, fibroblast formation, and re-epithelialization, happens from day 3 to day 21 post-injury. The maturation phase occurs from day 21 to 1-year post -injury, aiming to maximize the strength and structural integrity of new wound-filling tissue, epithelial growth, and scar tissue formation. These three phases influence each other, and many cells and cytokines are involved in each step. The number of studies on the wound healing process to achieve satisfactory results with a shorter time than the normal phase has resulted in a more detailed theory of the wound healing process which will be explained from the aspect of cellular and molecular mechanisms. ${ }^{6,17}$

Radiography is the most frequently used technique to develop the healing process in clinical practice. It can interpret callus formation, fracture line fracture, alignment, and complications such as delayed union or pseudarthrosis. In addition, the radiation dose given is relatively small, and the estimated cost is also low. Although conventional radiography is of limited value for assessing the fracture process, it is still the most widely used radiographic technique. All other standard radiographic procedures or modifications have their limitations. Therefore, conventional radiography is currently considered the most favourable diagnostic tool for evaluating fracture healing. ${ }^{9,10}$

Osteoblasts and osteoclasts have an important role in the bone healing process which can be assessed from conventional radiographs and histopathology. Conventional radiographs provide an image of the callus that will be seen starting from the proliferative phase. This image is a parameter of bone healing. In addition, the number of osteoblasts and osteoclasts seen from histopathological examination indicates the healing process has been completed or not. Based on the description above, the writer is interested in this research.

\section{MATERIALS AND METHODS}

This research has received approval from the Research Ethics Commission Universitas Padjadjaran Bandung. This preliminary study used 12 male Wistar rats with an incomplete fracture in the right femur made by a dental tapered bur with $0.3 \mathrm{~mm}$ in length and $0.2 \mathrm{~mm}$ in depth (Figure 1). Digital radiographic examinations were carried out on days $0,5,10,17$, and 25 after fracturing in a lateral position. Furthermore, a radiographic analysis was performed using Image-J to obtain changes in the value of length and depth in the healing area. The number of osteoblast and osteoclast was calculated by microscope. The analysis was performed to find the radiopaque and radiolucent patterns and the number of osteoblasts

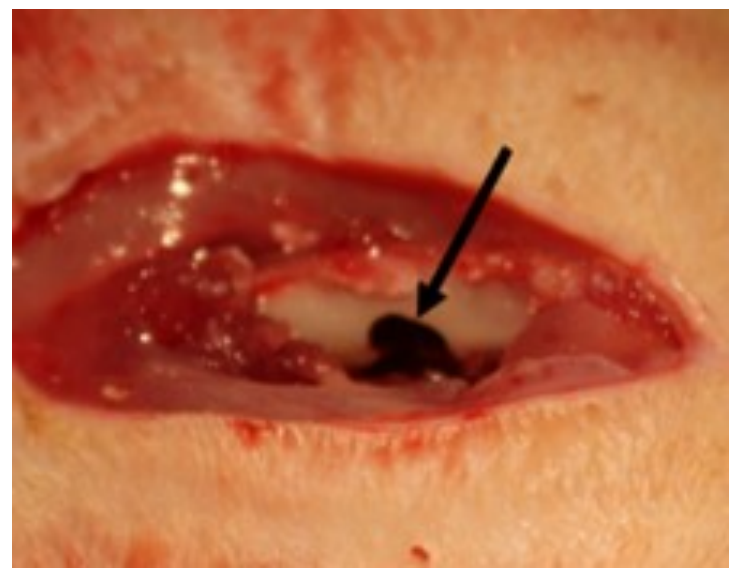

Figure 1. Distribution of CBCT-3D Examination Referrals in Dental Hospital Universitas Airlangga based on the origin of the referrals 


\section{ORIGINAL RESEARCH ARTICLE}

and osteoclasts. The study results were in a fracture areas with a smaller distance from day 0 to radiograph pattern, osteoblast and osteoclast day 25 (Figure 2 and 3). The bone healing process levels, and their relationship used ONE Way ANOVA begins with granulation tissue formation, followed statistical analysis.

by the gradual replacement of the connective tissue and bone. This process is comparable to the

RESULTS increase in osteoblasts up to day 25 , which blocks bone resorption. Osteoclasts regulate bone resorption, and their number increases after 10 and

This study resulted in a change in the 17 days to replace bone formation (Figure 4). radiograph pattern. Callus formation resulted in Osteoclasts decline after 25 days because

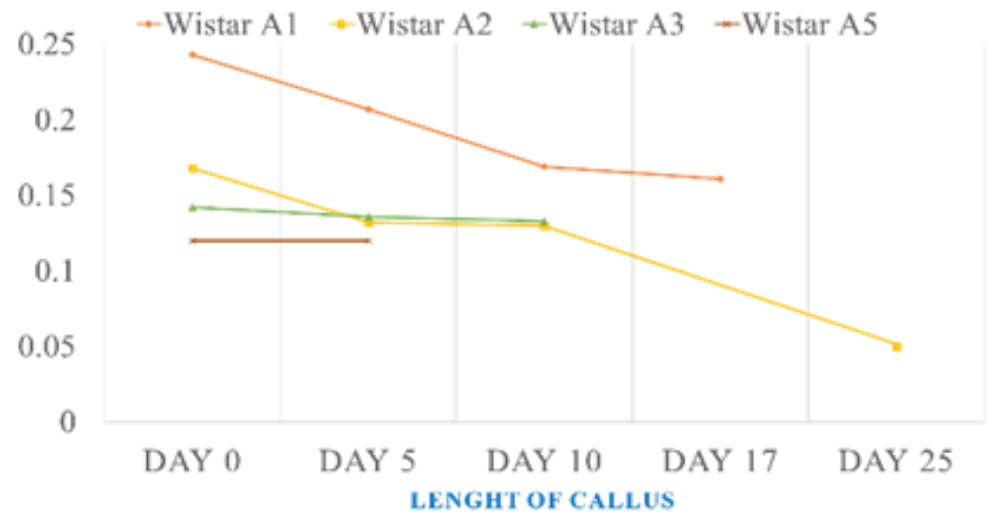

Figure 2. Length $(\mathrm{mm})$ of callus Day 0-25

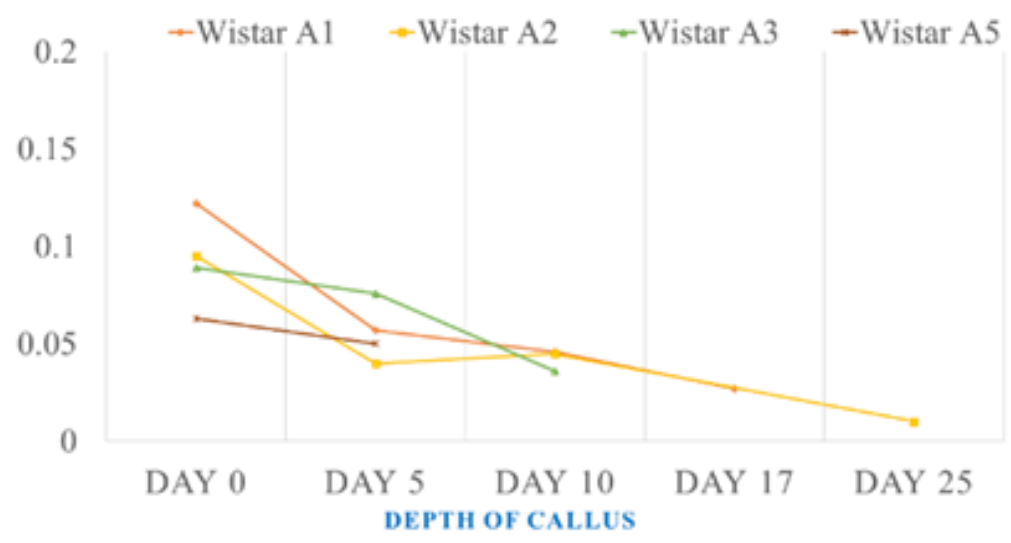

Figure 3. Depth $(\mathrm{mm})$ of callus Day 0-25

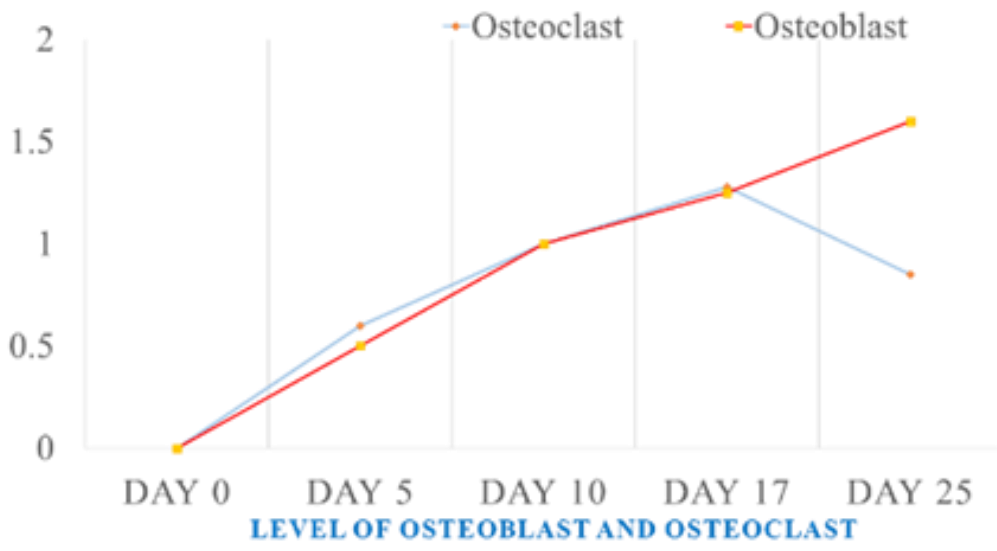

Figure 4. Level of osteoblast and osteoclast Day 0-25 


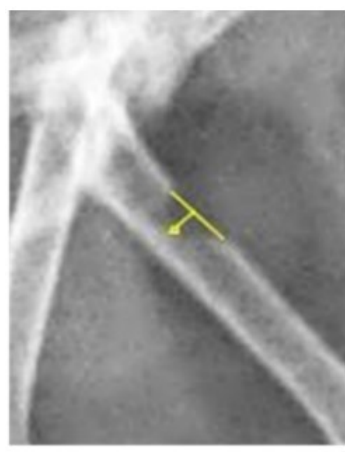

DAY 0

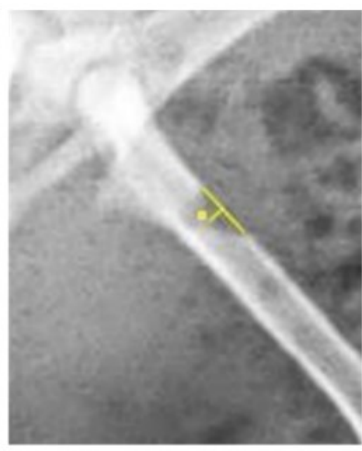

DAY 5

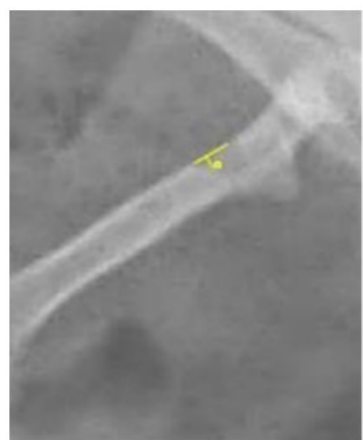

DAY 10

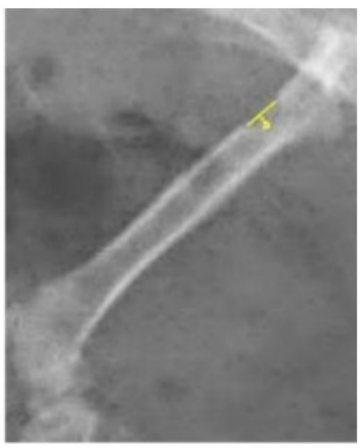

DAY 17

Figure 5. Callus Formation on Day 0-17

osteoblasts inhibit them, which control bone formation. Figure 5 shows that the formation of callus increased with increasing days.

\section{DISCUSSION}

Bone is an active tissue that will undergo continuous physiological remodelling. This process consists of bone formation by osteoblasts and bone resorption by osteoclast activity. This process is lifelong and allows new bone formation as long as calcium homeostasis remains sufficient for this activity. This process is accomplished and regulated by various actions of systemic hormones and local mediators. ${ }^{11,12}$

There are two forms of bone fracture healing namely primary and secondary. Primary bone healing occurs when bone fragments adhere tightly under compression from implantation. There is no callus formation, and the two bone fragments are joined and healed directly by osteoclast and osteoblast activity. Secondary bone healing is the most common form of bone healing, occurring when there are small cracks at the fracture site. Interfragmentary movements lead to soft callus formation, leading to secondary bone formation via intramembranous and endochondral ossification. This form of bone healing begins with the analytic phase and overlaps with the catabolic phase when the callus volume is reduced. Following this process, the bone remodeling phase begins with coordinated osteoblast and osteoclast activity over several months. Callus tissue will be reabsorbed, and bone will be formed. ${ }^{13}$

Fracture healing is a complex process that includes inflammation, repair, and remodeling (Figure 6). The first phase is the inflammatory phase. This phase begins when the injury occurs, damages the blood vessels, induces hematoma formation, and releases inflammatory mediators. The result of this phase is the formation of a bone callus. This phase lasts 5-7 days. The next stage is the repair phase. This stage lasts $4-40$ days after the first trauma. In this phase, the callus develops, and its growth is $40 \%$ of the healing process. Hematoma and callus form changes into mature callus structures caused by the growth of mediators, protein, and calcium so that callus can be seen radiographically. The last stage is the remodeling phase. This phase accounts for about $70 \%$ of the healing time, occurring within 1-2 years. The hallmark of this phase is a continuous process of bone formation and resorption, the result being the formation of new tissue. ${ }^{11}$

A series of healing processes will follow each fracture. The bone healing process is a series of cellular and molecular processes involving the inflammatory and proliferative phases and ends with the remodeling phase. ${ }^{14}$

When a fracture occurs, mesenchymal stem cells (MSC) from the local surrounding tissue and the systemic circulation enter the fracture site, proliferate, and differentiate into chondrocytes and osteoblasts. ${ }^{15}$ Osteoblasts can stimulate osteoclast formation and bone resorption by increasing RANKL

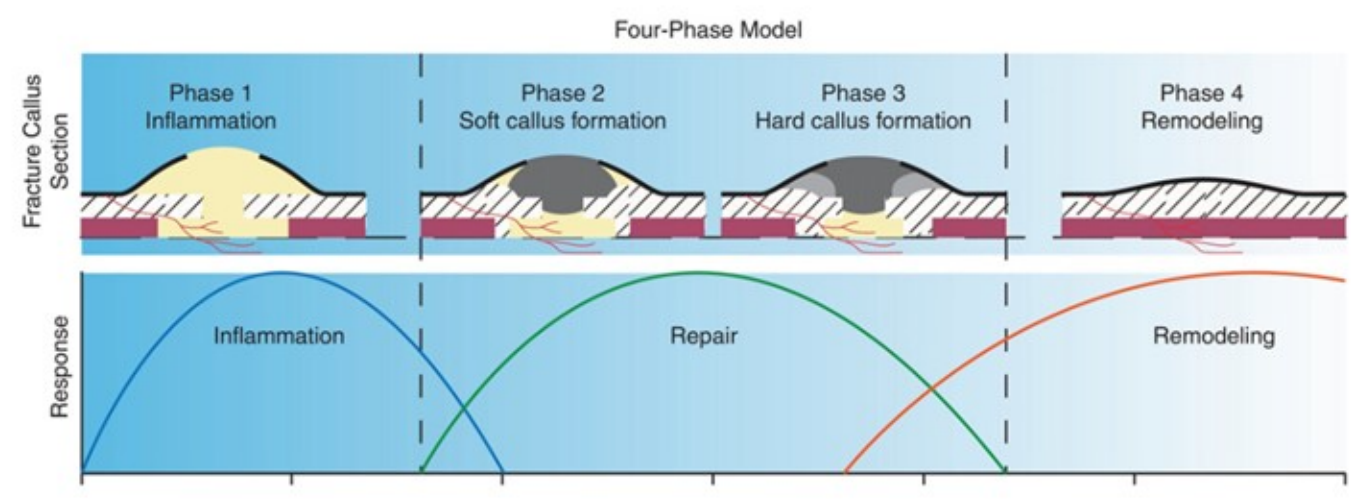

Figure 6. Schematic of 4 phases for fracture healing ${ }^{13}$ 
formation and decreasing OPG. Osteoclasts originate from the differentiation of monocytes/ macrophages found in bone. Differentiation and function of osteoclasts are mainly regulated by several factors, namely Macrophage ColonyStimulating Factor (M-CSF), Receptor for Activation of Nuclear Factor Kappa 8 Ligand (RANKL), and Osteoprotegerin (OPG). ${ }^{16,17}$

MSC differentiation provides several chondrogenic and osteogenic cells. Under the right conditions, they will begin to form bone and form cartilage in some cases. Some osteoclasts are ready to clean up dead bone in some of these cells. Together with islands of immature bone and cartilage, a thick cellular mass forms a callus or skeleton on the periosteum and endosteum surfaces. As the immature mineralized bone becomes tougher, movement at the fracture site decreases progression and the fracture fuses. ${ }^{18}$

This phase begins when injury and damage to blood vessels induce hematoma formation and releases inflammatory mediators. The result of this phase is the formation of a bone callus. In this phase, the callus develops, and its growth is $40 \%$ of the healing process. Hematoma and callus form changes to mature callus structures caused by growth mediators, protein, and calcium so that callus can be seen radiographically. The last stage is the update phase. The hallmark of this phase is a continuous process of bone formation and resorption, the result being the formation of new tissue. $^{11}$

Osteoblasts and osteoclasts can be used as parameters for the severity or cure of a disease. If a bone fracture occurs, the number of osteoblasts will increase, indicating the remodeling process in the fractured bone. Osteoblast cells play a role in bone formation and regeneration by producing, secreting, depositing, and mineralizing the bone matrix. In the callus formation phase, the number of osteoblast cells has not reached the standard value because they continue to increase until they reach their peak value in the remodeling phase. The number of osteoblasts will return to average values after the remodeling process is complete and the healing process has ended. ${ }^{7,8}$

Callus formation and growth are critical in secondary fracture healing. Callus growth can be observed radiographically and measured using the callus length. ${ }^{19,20}$ The callus index can usually be calculated from conventional radiographs obtained during routine follow-up of fractures. Digital imaging gives the best measurements, but manual measurement with visual eyes and a ruler can be an alternative. Digital image analysis is up to 20 times more accurate. Still, in this particular application, any errors generated by the eye are unlikely to influence the results significantly. Excessive variations in radiographic exposure can alter the appearance of the callus. Overexposure reduces the apparent size of the callus, while underexposure can give the impression that soft tissue shadows are callus. The quality of radiographs has improved with digital radiography to reduce this problem. ${ }^{19}$

\section{CONCLUSION}

The conclusions were obtained there are changes in the radiograph pattern. The radiopaque increased while the radiolucent decreased; the osteoclast pattern tended to be stable and lowered while the osteoblasts increased during the fracture healing process. The correlation of all the factors is very closely related.

\section{ACKNOWLEDGMENTS}

None.

\section{FOOTNOTES}

All authors have no potential conflict of interest to declare for this article. This research was registered and approved by the Research Ethics Committee Universitas Padjadjaran Bandung with the registration number of 959/UN6.KEP/EC/2020. All procedures conducted were in accordance with the ethical standards.

\section{REFERENCES}

1. Oryan A, Monazzah S, Bigham-Sadegh A. Bone injury and fracture healing biology. Biomed Environ Sci. 2015;28(1):57-

2. Fikri M, Azhari A, Epsilawati L. Gambaran kualitas tulang pada wanita berdasarkan kelompok usia melalui radiografi panoramik. J Radiol Dentomaksilofasial Indones. 2020;4(2):5.

3. Mock C, Cherian MN. The global burden of musculoskeletal injuries: Challenges and solutions. Clin Orthop Relat Res. 2008;466(10):2306-16

4. Riskesdas. Riset Kesehatan Dasar [Internet]. Jakarta; 2018 Available from: http://www.depkes.go.id/resources/ download/info-terkini/materi_rakorpop_2018/Hasil Riskesdas 2018.pdf

5. Kovtun A, Bergdolt S, Wiegner R, Radermacher P, Huber-Lang $M$, Ignatius $A$. The crucial role of neutrophil granulocytes in bone fracture healing. Eur Cells Mater. 2016;32(Cxcl):152-62.

6. Einhorn TA, Gerstenfeld LC. Fracture healing: mechanisms and interventions Thomas. Nat Rev Rheumatol. 2015;11(1):45-54

7. Sabri M. Administration's Effects of Ethanol Extract of Cissus quadrangularis Salisb on Growth of Lumbal Bone in Ovariectomized Rats. Natural. 2013;13(2):48-54.

8. Jayakumar $\mathrm{P}, \mathrm{Di}$ Silvio $\mathrm{L}$. Osteoblasts in bone tissue engineering. Proc Inst Mech Eng Part H J Eng Med. 2010;224 (12):1415-40

9. Blokhuis TJ, De Bruine JHD, Bramer JAM, Den Boer FC, Bakker $F C$, Patka $P$, et al. The reliability of plain radiography in experimental fracture healing. Skeletal Radiol. 2001;30(3):151 -6 .

10. Gunawan G, Sitam S, Epsilawati L. Densitas tulang mandibula pengguna obat anti hipertensi calcium channel blocker (CCB) melalui radiograf panoramik. J Radiol Dentomaksilofasial Indones. 2020;4(2):1.

11. Epsilawati L, Satari M, Azhari. Analysis of Myrmecodia Pendens in Bone Healing Process to Improve the Quality of Life: Literature Review. IOP Conf Ser Earth Environ Sci. 2019;248(1).

12. Chen WT, Han DC, Zhang PX, Han N, Kou YH, Yin XF, et al. A special healing pattern in stable metaphyseal fractures. Acta Orthop. 2015;86(2):238-42.

13. Ghiasi MS, Chen J, Vaziri A, Rodriguez EK, Nazarian A. Bone fracture healing in mechanobiological modeling: A review of principles and methods. Bone Reports [Internet]. 2017;6:87100.

14. Haffner-Luntzer M, Fischer V, Prystaz K, Liedert A, Ignatius A. The inflammatory phase of fracture healing is influenced by oestrogen status in mice. Eur J Med Res. 2017;22(1):1-11. 
15. Sathyendra V, Darowish M. Basic science of bone healing. Hand Clin [Internet]. 2013;29(4):473-81.

16. Utomo DN. Defek Kartilago Sendi Lutus. Surabaya: AIRLANGGA Unversity Press; 2018.

17. Lerner UH. Osteoblasts, Osteoclasts, and Osteocytes: Unveiling Their Intimate-Associated Responses to Applied Orthodontic Forces. Semin Orthod [Internet]. 2012;18(4):237-48.

18. Buza JA, Einhorn T. Bone healing in 2016. Clin Cases Miner Bone Metab. 2016;13(2):101-5.

19. Eastaugh-Waring SJ, Joslin CC, Hardy JRW, Cunningham JL. Quantification of fracture healing from radiographs using the maximum callus index. Clin Orthop Relat Res. 2009;467 (8):1986-91.

20. Salih S, Blakey C, Chan D, McGregor-Riley JC, Royston SL, Gowlett S, et al. The callus fracture sign: a radiological predictor of progression to hypertrophic non-union in diaphyseal tibial fractures. Strateg Trauma Limb Reconstr. 2015;10(3):149-53. 